\title{
ORGANIZATIONAL LEARNING AND BUSINESS STRATEGY IN A CRITICAL SITUATION
}

\author{
Takeshi Nakayama ${ }^{a}$, Satoshi Momotake ${ }^{b}$ \\ a Yokohama City University, Kanagawa, Japan \\ b Osaka University of Tourism, Osaka, Japan \\ Corresponding email:nakayama888@gmail.com
}

\begin{abstract}
This paper takes a step away from the conventional organizational learning theories and builds and verifies a new model of organizational learning when a particular critical situation occurs. For this reason, in addition to "Single-Loop Learning" and "Double-Loop Learning," which are the theories of conventional organizational learning, a new model that adds "Creative Learning" is used. As an example in the critical situation of the 2011 Tōhoku earthquake and tsunami, we took up 2 companies (Renesas Electronics Corporation, Naka Factory and Hitachi Transport System, Ltd) and analysed how this model could be applied.
\end{abstract}

Keywords: Business Strategy, Organizational Learning, Critical Management, Case Study.

\section{Introduction}

In order to sustain the competitiveness of a company, it is supposed that organizational learning is important. Moreover, especially in a Japanese company, an important element of this organizational learning is deep competitiveness (Fujimoto, 2005). This deep competitiveness clarifies the methods utilized by the human resources department inside a company, trains a generalist, thinks of teamwork as vital, places equal importance on "communication" and "action," and has OJT and Kaizen as its strongest points. In this paper, the technique for securing the maintenance of competitive power, which utilizes these human resources for convenience, is summarized, and it is called "genba power." Incidentally, genba power has increased through the routine work that is represented by the Toyota Motor Corporation.However, routine work does not necessarily exist as the driving force of a company. In fact, the assumption of non-routine work is used within limits in many cases. This assumption was taken up by the routine work by the Kaizen movement. However, the Tōhoku earthquake and tsunami disaster which occurred in 2011, which was a simultaneous occurrence, and the subsequent radiation leak accident of a nuclear power plant became an unexpected 
occurrence which affected routine work on a level known asthe Kaizen movement.

Withregards to organizational learning under such an unexpected critical situation, an analysis framework is still insufficient. In this paper, the enforcement of an organizational learning theory is tried by clarifying organizational learning under a critical situation similar to this.

\section{The Review of Precedence Research}

The resource-based view of J.B.Barney is the starting point of this paper in analyzing organizational learning under a critical situation. The logical framework, which takes the lead in this resource-based view, is the Value, Rarity, Imitability and Organization (VRIO) framework. This VRIO framework can estimate whether the resources and capabilities that a company owns are competing.

This paper will promote the discussion which focuses on the VRIO model for organizational learning as a process of formation of organizational knowledge and scarce resources with high inimitability. However, J.B. Bernie is mainly analyzing American companies and this has become the theory to describe U.S. companies. The companies in Japan that are the subject of the research of this paper have a fundamental cultural difference with the United States. For example, while Japanese companies generally train a generalist, the employment of a specialist is common in the United States. Even if this is the same type of organizational learning used in Japan and the United States, it cannot be overemphasized that a difference arises in the technique and effects. In this paper, the contents of these differences are excepted and suppose that they are limited to an analysis of Japanese companies. In addition, the arrangement of the theory of organizational learning, the theory of organizational ability, and the theory of the organizational learning under a critical situation are also performed.

\subsection{Organizational learning}

The research on organizational learning was made briskly in the 1990s.About the research genealogy of this organizational learning, Ando (2000) performs a literature survey which entails: (1)the Argyris system (the organization members of all the layers that constitute an organization) where the research for realizing "study for study" is according to each position; (2)the organizational learning theory of March systems (change should arise to the existing organization routine and pass the selection research of results in fixing any mistakes); (3)and research that could be classified into the group about unlearning based on the Hedberg systems (research of top management employees or the top group of an organization to carry out unlearning on the fight into organizations at the company level which already lacked validity) was done.

Under these circumstances, the indication that organizational learning leads to the capability of an organization has also been concluded.

\subsection{Organizability}

The argument on organizability is a concept that has progressed from the resource-based view of organizational learning. Itcan be understood that organizational learning progresses one step

Asia Pacific Institute of Advanced Research (APIAR) DOI : 10.25275/apjabssv4i1bus8 
from a viewpoint called necessity that human resources return Satoru to an organization, like organizational learning.

to Sakamoto (2007), it is said that it can be understood as A.D. Chandler has defined organizability. Hitting at the coreof the driving force of "development by industrial capitalism was organizational ability, which a company as a synthesis has. Such organizational ability was the set of physical plants and human skills systemized inside a company. They included the skill of the employee who is workingat many different physical plants and each field unit, such as a factory, place of buainessorresearch."And "companies compete by domestic and an international market. It is assumed that it was limited to when an institution and skill were adjusted carefully, unified under the notice of a scale required to maintain growth and the range can be attained." Furthermore, "the organizability with which a company was endowed yields the profit which is sufficient for supplying many funds required for continuous growth, and has begun to come out ahead. Furthermore, organizability presupposes the importance of the specialized skills that gives a company predominance in the foreign market or a correlative industry was offered. It seems that, namely, it is expected that the Chandler model has become a factor which will bring about further growth once a company forms organizability in the process of the corporate activities."

According to Fujimoto, (2003), especially in a Japanese company, it is indicated that it is considered "a thing which is of the power of an organization peculiar to each company (or company group) as for which repetition can carry out things that generally need 'organizability' in order for a company to prosper and survive." That is, the special features of organizability are summarized as five points. First of all, it differs with companies. Secondly, it is the literal attribute of an organization. For example, it is not considered organizability for the talent or the genius of one person to be used who was working on the register by chance. The third, importance is given to "competitive power," and the difference of the competitive power between companies is brought about. The fourth point is the organization routine thatanother company cannot easily imitate.Finally, it is indicated by that which is built by "organizational learning."

Takahiro Fujimoto analyzed this further by dividing organizability into "surface competitiveness" and "deep competitiveness." Takahiro Fujimoto has named the competition which raises this organizability and which has gone to accumulate capability construction competition. The definition of this capability construction competition assumed that it is supposed that "product development is a production of the design information, and creation is transcribed from a production process to the design information." 1)Routine structure capability is further defined as: repeating the competitive power at a higher level than the others, and realize, 2)routine improvement capability: raise competitive power at a speed quicker than the others, and 3)Capability construction competition: supposing that there is a step above the stage of organizational ability of building the organizational ability of the two above-mentioned at a speed quicker thanother companies. 
And, especially in order to heighten this organizational ability, the view referred to as being on the spot from "genba power" has also come out from the depths of competitive power. The positioning of genba power based on Takahiro Fujimoto's capability construction competition is shown as follows, With this paper, genba power is specified.

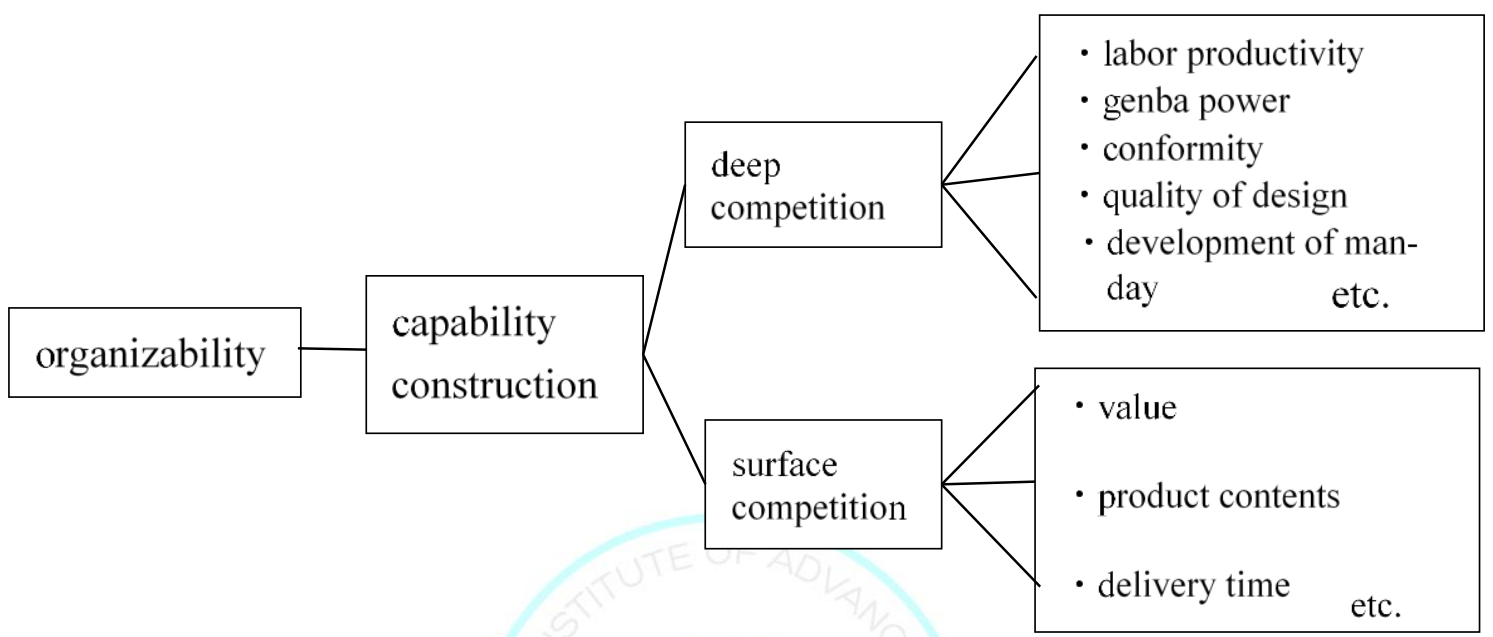

Figure1: Composition of Organizability

\subsection{Organizational Learning Theory During a Critical Situation}

Organizational learning and the argument on the organizability on the extension had the main capability improvement research done on a series of organizational activities performed at a routine place of employment. I can arrest the Kaizen motion with the correspondence exercise to a non-conventional rules situation that occurs through routine work, but when these nonconventional rules situation occur in a factory deal, it becomes routine when I change the viewpoint.

The environment, which surrounds a company, is changing every moment. When a natural disaster is in a state in which it cannot be dealt with using the usual Kaizen movement, that is when a critical situation may occur. In order to resume the production activity again in the case of corporate activity and production, it falls ontheperformanceof organizational learning under a critical situation. This phenomenon has been studied by such as CaroleLalonde,(2007) and Christopher Simmons, (2009).

Lalonde, (2007) submitted a three-step approach to analyze the organization learned from the natural disaster and how an organization could learn from the process of risk management.1)Ask how is the organization in an extreme situation adapted for the first crisis.2)Look at the setup of a target in an extreme situation and draw a result (single-loop learning). 3)Look at developing and learning from an action plan for goal achievement (doubleloop learning).There are four stages in this crisis:1)crisis stage;2)a sharp crisis stage;3)chronic 
crisis stage;4)crisis solution stage.

Moreover, Simmons,(2009) discussed risk management and organization development from the viewpoint of risk management. The following wasused as a framework of the organization in that case:the development of the new model of organization development, the security of organizational learning which continues indefinitely, and, most importantly, risk management that was independent until now was usually put into an organization.

Moreover, organizational learning was further classified:1)critical state;2)acceptance of a study;3)single-loop learning;4)double-loop learning; and 5)Kaizen. And organizational learning was considered to be from 2) to 4).First, at 2), an organization begins the acceptance of a critical situation.It is said that a critical situation is the basis of capability and knowledge, an environmental change or the target change, and is used to ascertain other changes. Single-loop learning (3)) is a stage where an organization performs training and the like based on the fixed contents. The organization of double-loop learning (4)) analyzes the occurrences of current days and the past. And it is at this stage where the success ofKaizenis determined.

\section{Verification Model Building}

Based on the review of previous work, the following verification models are built in this paper. First, the viewpoint of organizational learning is left, and organizational learning is divided into six stages in order to verify the influence of genba power had on the organization during a critical situation. First of all, 1) when a critical situation occurs, 2)organizational learning starts. 3)This organizational learning is the acceptance of the Stage I 4) the single-loop learning of Stage II , and the double-loop learning of StageIII.5) this stageIII is recognized as a variable which made visualization and sharing of information further independent. Then, 6) it develops into StageIVwhichisa multi-skilled worker system and a promotion system, which is an improvement in an organization made by exertion of emergency power including the knowledge-creation by long-term employment. In addition, the limit corresponding to a manual and expression are possible for this improvement. When an organization is under a critical situation, it cannot always respond by QC or BCP (business continuity plan), which are usually prepared. This limit utilizes the organizational ability accumulated until now, and the way of thinking that critical situation will be overcome by practical skills produced in an organization. It is as follows when the scheme of this Kaizen is conceptualized: 


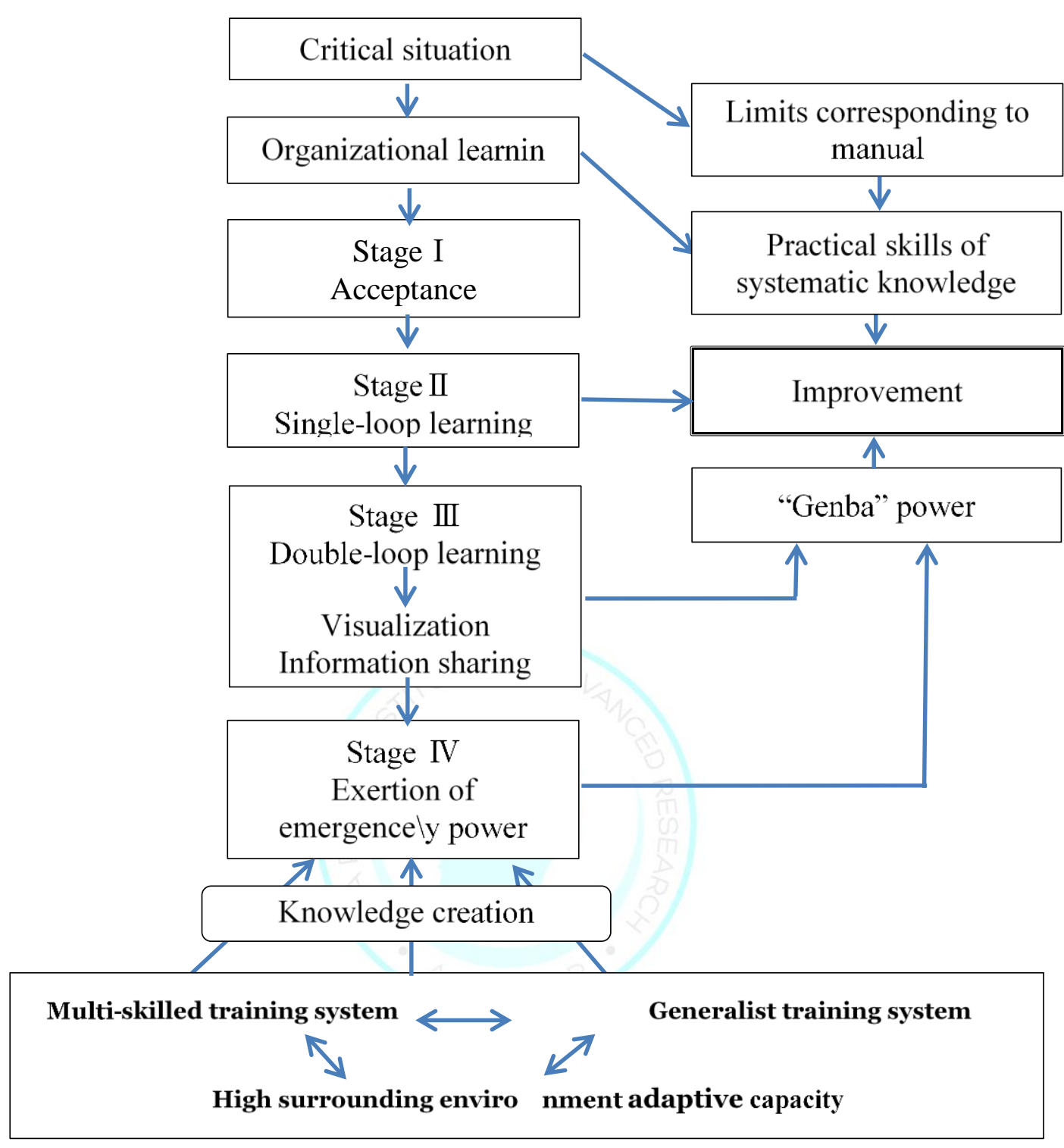

\section{Figure2: Crisis Model of Japanese Companies}

1) The generation of a critical situation: The limitation of manuals (QC, BCP, etc.)

When the situation occurs where an organization cannot respond with the usual routine work (of course, routine movement by the Kaizen movement of the non-routine work situation generation is also included in this case), it means having developed into a situation where it cannot respond by the manuals upon which it was decided conventionally. Although the generation of the critical situation in the case of this paper refers to the Tōhoku earthquake and tsunami which occurred on March 11, 2011, the model of the natural disaster before this occurrencewas the Great Hanshin earthquake. The standards of the BCP (Business Continuity Plan), which a country advocates, can also actually be said that many places 
depended on learning from the Great Hanshin earthquake.

2) The start of organizational learning: Acceptance of a critical situation (Stage I )

If a critical situation occurs, the activity will stop a company temporarily. This stop occurs during a special situation, which is not included in the usual corporate activity, and in order to overcome this situation, a company must grasp the damage caused by the situation, and then try to look at the whole picture of the critical situation. It is during the state of acceptance of a critical situation where the remedy can be drawninstead of groping in the dark during a critical situation.

3) Single-loop learning (Stage II )

Single-loop learning is a plan of problem solving according to the view that it already has occurred, or the framework of action has been set, as Donald Sean has made reference to.

The trial that is going to cope with it until now, for example by the manual, has been carried out after the critical situation generation is made. Although this becomes the start of organizational learning, in performing organizational learning, various methods are attempted, such as the QC movement or theKaizen movement. Of course, the practical use of BCP in preparation for the cases where a critical situation occurs is very important for the continuation of the production of a company. This is single-loop learning.

4) Double-loop learning $\rightarrow$ Visualization, information sharing (StageIII)

Double-loop learning is throwing away the existing framework and taking a new view and framework of action, like single-loop learning, as Donald Sean has also made reference to.

After a critical situation occurs, an organization acts based on the existing framework, but the situation that does not work at all will continue. In this case, it looks at howan organization is working and an examination is made about how a new framework should be built. This is double-loop learning.

5) Exertion of emergency power-Knowledge creation (Multi-skilled training system、promotion system、 long-term employment)

In the new framework,which doesn't exist yet, individual knowledge provides organizational learning from all aspects and looks at how it links with an organization based on the concept of knowledge creation.

\section{Generation of a Critical Situation, and Situation Management}

The Tōhoku earthquake and tsunami which occurred on March 11, 2011 brought about serious damage to the Pacific coast area, when the tsunami also flooded the Tôhoku district. Although the direct damage at the earthquake disaster time was natural, in addition to the damage of roads and railroad tracks, which were divided, the delays in restoration of transportation routes including air routes,led to the calamity sufferedby ordinary citizens in their attempts at refuge and restoration. The damage of infrastructure included even more than just the roads, railways, and airways, but also caused dysfunction in terms of the distribution control of goods, and even the productivity of the supply chain was destroyed by the Self-Defense Forces in the various companies involved in restoration efforts. This is a glimpse of the enormous damage of the 
supply chain production, especially if you look at the logistics stagnation which led to a speedy recovery after efforts by the U.S. military.

Rather than only the central areas being affected by the Tōhoku earthquake and tsunami, such as Iwate, Miyagi, and Fukushima in the Tohoku region, the scale was different in the Northeast three Prefectures, such as Ibaraki Prefecture and the adjacent area, but the effect of earthquake in the Kanto district was not a small impact, and companies located there were damaged both externally and internally.

The Tōhoku disaster was a complex combination of an earthquake, tsunami, and a nuclear power plant disaster, as described above.By the estimation made by the Cabinet Office, the total cost of damage was about 16.9 billion yen. When the earthquake damage in Ibaraki was surveyed, apower failure occurred due to the earthquake and cell towers were knocked offline which led to mobile phones in the area from being used, anda the destruction of a wall that was mostly visible to the eyes, led to it eventually collapsing. Immediately after the earthquake, major traffic signals of the National Highway No. 50 bypass Reformer neighborhood were without lights and streetlights did not come on at night. Of course municipal and other lifelines were also affected. The road had prevented the passage of cars due to it being raised by the earthquake. One could easily imagine that the damage of the manufacturing industry in the prefecture suffered greatly from this situation as well.

\section{Correspondence of a Company to a Critical Situation}

Based on a verification model, data was analyzed about the production base of a microcomputer which was required in order to control a hybrid car corresponding to the environment of the Toyota Motor Company through this case study, the Renesas Electronics CorporationNaka Factory and the Hitachi Transport System, Ltd., which was the central physical distribution company in Ibaraki.

A country and a municipal corporation was performed dealing with the critical situation first. FollowingtheTōhoku earthquake and tsunami which occurred on March 11, a country and Ibaraki Prefecture actually started the examination about relief goods supply for a disaster countermeasures office for installation as the first step immediately following the earthquake, and the emergency assistance goods to Ibaraki Prefecture began to arrive on March 16 after that. In addition, there were other needs, such as temporary staffing to provinces from the Kanto District Transport Bureau on the 17 March, logistics to the department responsible for the county, and security. Traditionally, problems have been pointed out for about five items for emergency transportation of goods, but the corresponding ad hoc provincial Trucking Association, that is, the genba power, and goods transport flexibility in order to respond to the disaster of unprecedented was to be performed. This is said for the "Iwate model" which the Iwate Trucking Association performed the same way, and to express the strong spot against an emergency.

From the Tōhoku earthquake and tsunami immediately after the logistic has been destroyed, cases covered in case studies will reveal how companies ensure the logistics, and about allowed

Asia Pacific Institute of Advanced Research (APIAR) DOI : 10.25275/apjabssv4i1bus8 
for normal economic activity.

\subsection{Renesas Electronics Corporation (Naka Factory)}

\section{( 1 ) Corporate profile}

Renesas Electronics Corporation is a company that was founded and became independent, then split up the enterprises of its company mainly by Hitachi, Mitsubishi Electric, NEC in 2002, and so on. In addition, the largest stockholder is Hitachi, and holds 30.62\% of stocks as of 2011. However, reorganization and consolidation have started under the influence of the worsening performance caused by the Tōhoku earthquake and tsunami in 2012. This is taken up in this paper about the factory of Naka Factory (Hitachinaka-shi, Ibaraki), which produces the key devices of the hybrid car produced by Toyota Motor also in this Renesas Electronics Corporation.

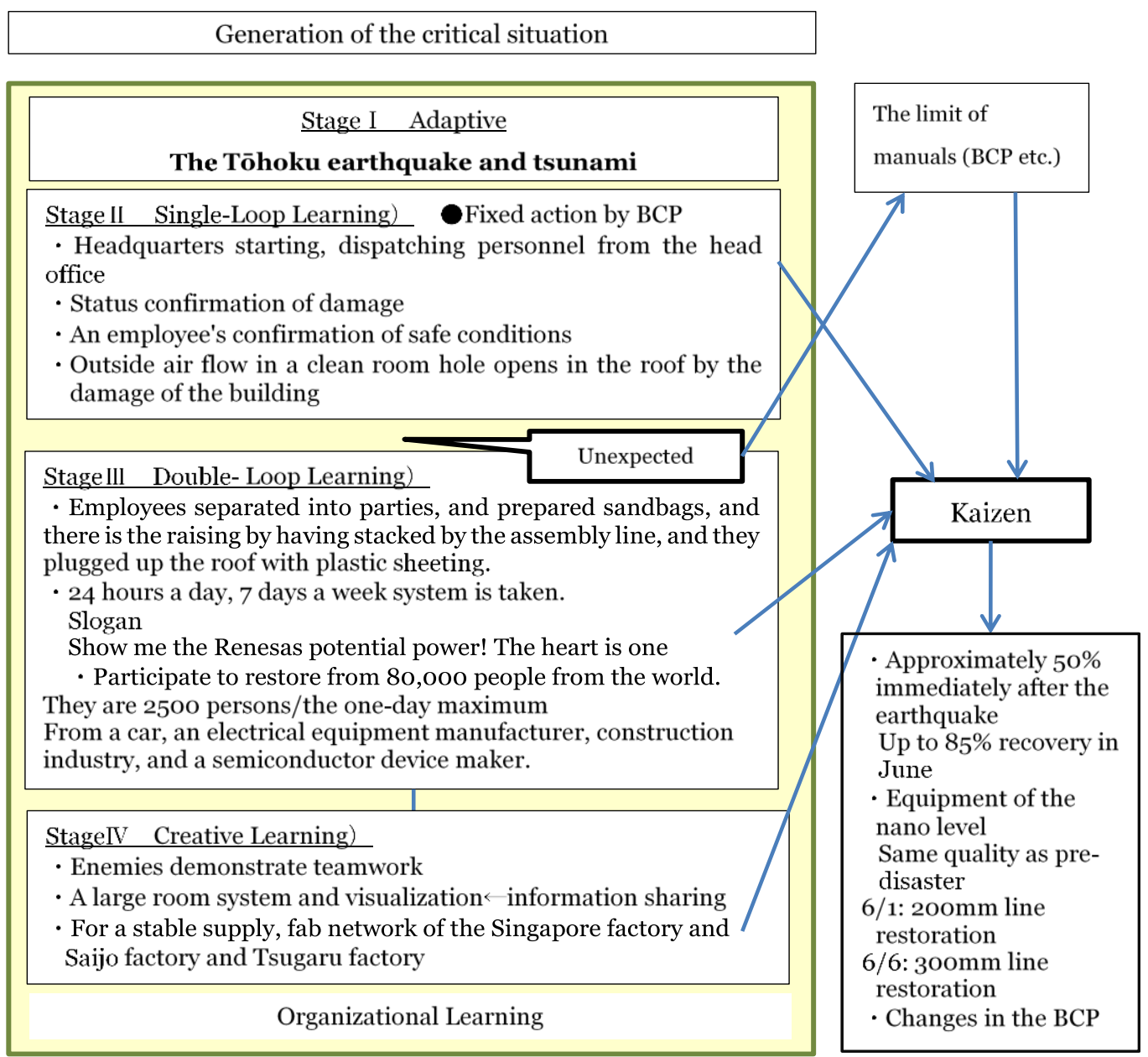

Figure 4. Case1(Renesas Electronics Corporation) 
( 2 ) The crisis of the organization collapse by the occurrence of the Tohoku earthquake and tsunami (critical situation).

On March 11, 2011, the Renesas Electronics CorporationNaka Factory was running normally. However, due to the earthquake, which occurred at 14:46, all the electric currents and lifelines of the Hitachinaka factory were cut off.

Since this Renesas Electronics Corporation Naka Factory is a chip fabrication factory, automation was necessary. Moreover, since nanotechnology was utilized and inferior goods were also generated which requiredthe absence of dust, most of the rooms in the factory werevery clean. However, a hole was made in the ducts in a factory by the earthquake. Furthermore, since the power failure occurred, it became difficult for a factory to be united like before and able to produce the goods. The factory itself tried to provide immediate information gathering which corresponded to the confirmation of safe conditions of the staff other than the employees engaged in work during the earthquake, and the restoration of three shift operations. However, the telephone line had been blown out and mobile phones were not working, it did not progress as it should, and the work of a term could not be done. That is, the crisis of organization collapse came.

( 3 ) Correspondence of earthquake disaster occurs (Stage I : Adaptive)

The idea of how things should be addressed by the Tōhoku earthquake and tsunami began: 1)the shutdown caused by a damaged of factory;2)the situation that did not take the confirmation of cleanliness of the clean room;3)the situation that could not provide adequate working safety for employees with destroyed lifelines; and 4) in such a situation how difficult it could be to confirm the safety of employees.

The Renesas Electronics Corporationestablished a task force in the head office based on the BCP which existed from the current protocols. In the Naka Factory, the task force consisting mainly of a factory manager and the administration division was being established, and it strived to assess the situation. The head office task force and the task force of the Naka Factory were always in contact, and after reporting the situation from the Naka Factory, they took a look at how the head office task force generalized the request which existed from the Naka Factory at its various posts as a whole, and responded to them.

(4) An individual employee's correspondence (Stage II : Single-Loop Learning)

Usually, in the organization in which specialists gather, if the staff in charge withdrew even by just one person, the organization and functionality of a company will become difficult for an unexpected situation like the Tōhoku earthquake and tsunami. However, since a generalist is in the mainstream in the cases of Japanese companies, even if the staff of an organization has a vacancy of some employees, the organizational design is made so that it can continue working as an organization.

In the Renesas Electronics CorporationNaka Factory, the task force was established based on the management procedures of when a crisis situation usually occurs, including the following:1) employees' safety check; 2) the grasp of the disaster situation of a factory; 3) and the repair work 
plan and the like were formulated. However, as stated above, it was hard to establish connections by telephone from around 16:00 on March 11 whentheTōhoku earthquake and tsunami occurred, and the safety check took about a day. In addition, since it was in the time fromthe late afternoon to the evening, and although the company checked whether reservations of safety and the continuation of operations would be possible for the time being, the full grasp of the disaster situation didn't happen until after March 12. It had even become a difficult situation to form a restoration plan at the time of the earthquake. Especially concerning individual employees, the spot was commanded to focus on the group leader class of the spot, and it strove for a grasp of the situation.

( 5 ) In the case of the earthquake disaster, consideration of what kind of correspondence as an organization to be used. (Stage III : Double- Loop Learning)

In the usual work procedure, the network was used in order not to be of use. Then, the personnel stationed in the parts of the usual business organization in their regular duties were put into small groups focusing on the group leader. And each member checked whether the contents of work, which was taken charge of in person at the time of routine work, would be executable. They checked when it was not able to carry out, and what kind of obstacles had to be overcome. This was performed after group leaders checked each one of the employees.

The contents of this check were huge, and while the lifelines were cut off and being unable to utilize the usual information processing systems, the work of groping in the dark continued. As a consequence, on condition that the clean room is a principal of the production was found to be damaged, under the circumstances it is not possible to use a PC or phones, and in the normal course of business, to secure the materials and personnel and information sharing it, was decided that no content made a systematic response as the center.

For the fence reason, organization took many talented people every day and hour for a week to reproduce this clean room, and in order to restore the parts of the building damaged, plastic sheeting and sandbags were used and the emergency measures were given.

Moreover, a sign with aslogan of revival, "Show me the Renesas potential power! The heart is one," was hung up and the employees' morale was heightened.

(6) The new measures at the time of the earthquake disaster restoration and revival (Stage IV : Creative Learning)

As a consequence of the earthquake, responding to contingencies was unable to be improved and normal exercises were forced, from sheer size, to maintain the chain of command, and the sharing of information and while planning for reconstruction purposes and recovery, they faced many challenges to dropping day-to-day operations for a while. This is the difficulty of the reservations of information sharing, a staff, and materials.

If it is the usual organizational learning, since it is carried out in the organization, fixed law can be found out through the study method. However, due to this Great East Japanese Earthquake causing such a calamity, it is under a supreme proposition called resumption of the routine work by early restoration, and secures a customer's surplus factor first by the Renesas Electronics 
Corporation Naka Factory for restoration due to the decline in the working efficiency by an employee's life itself having suffered a great deal of damage. Subsequently, the dispatching personnel from the non-stricken area of Hitachi, which is a main stockholder, NEC, and Mitsubishi Electric were secured.

However, since a total of 80,000 employees were without experience and worked at the Renesas Electronics Corporation Naka Factory participated, information sharing became the most difficult work. It is because it was seen as an enemyof Renesas Technologies. However, the group leaders classed beyond the length-of-service of five years became important here. And the company cafeteria was used as a meeting space andwas used as the front headquarters in order to perform information sharing, and with the use of a white board, the work of forming the repair work itself into routine work was done, and restoration became a serious prospective during March.

Moreover, the alternative factories of production were also positively prepared towards the early recovery of the quantity of production. These were the Tsugaru factory, the Saijo factory, and the Singapore factory. This is emergent Kaizen movement to the early restoration of production which was not able to respond in the conventional BCP.

\section{Conclusion}

The verification model built until now is based on the theory of the organizational learning during a critical situation was utilized, and the example of the Renesas Electronics Corporation Naka Factory in Hitachinaka-shi, Ibaraki and Hitachi Transport System, Ltd. which has a base in Hitachi-shi, Ibaraki was analyzed using the organizational learning during the critical situation of an organization called the Tōhoku earthquake and tsunami.

When both companies were compared, in the preparatory step before critical situation generation, it turned out that there is a decisive difference. As for this, the Renesas Electronics Corporation was preparing the BCP in advance. The point of difference is that Hitachi Transport System, Ltd. did not prepare a BCP.InStage II, the BCP of Renesas Electronics Corporation was not able to function effectively in the Tōhoku earthquake and tsunami, as verified by the verification model. Moreover, in the contingency situation learned until now, it was not able to respond to Hitachi Transport System, Ltd. that was not preparing a BCP. That is, although the Tōhoku earthquake and tsunami was an unexpected occurrence for both companies, it can be understood that it was also what similarly shows the limits of a manual.

For this reason, although it shifted to StageIII, both companies began to grope on the extension corresponding to the conventional contingency situation. Since the BCP was prepared in advance at the Renesas Electronics Corporation Naka Factory, only grasping of the damage situation could be performed. However, since the damage was over the range of assumption, in single-loop learning, Stage II could not respond, but became inefficient. Although it was going to carry out Stage II for Hitachi Transport System, Ltd., as well as for Renesas Electronics

Asia Pacific Institute of Advanced Research (APIAR) DOI : 10.25275/apjabssv4i1bus8 
Corporation, the company had not experienced this until it now became inefficient.

The organizational behavior which took a step forward rather than the contingency situation corresponded upon which it was decided conventionally or, which was experienced as a result of examining how these critical situations are overcome came to be seen. This is StageIII. In Stage III, the Renesas Electronics Corporation adopted human-wave tactics. Moreover, in Hitachi Transport System, Ltd., it came to form the plan of the transportation route in person instead of administration for the purpose of early preservation of transportation routes. By this, in Stage III which both companies performed by fixed (the existing experience), and Stage, which corresponded to the critical situation of the organization flexibility, since both were not able to respond by Stage II , it shifted to Stage III.And those of Stage III had improved the performance of the organization than Stage II at that time.

Furthermore, individual knowledge and the knowledge of the organization united also in the both companies which exceeded the fixed (the existing experience) framework of StageIII.The organizational learning that was carried out was able to be clarified by a large room method or visualization of work, and so on, at the Renesas Electronics Corporation, and about Hitachi Transport System, Ltd., improvement activities such as stacking or fumbling in the field was performed. This is StageIV.

In the Renesas Electronics CorporationNaka Factory, the knowledge of the individual of the competitor, which does not enter into organizational learning until now, was embedded in the organization of the company. In order to utilize the individual of a different organization on condition of teamwork, as part of a team of the company, the large room system shared information. About Hitachi Transport System, Ltd., the talented people on the spot were utilized, and the checking of alternative transportation routes was able to be divided among itself, and it was able to be carried out promptly, and also was able to obtain prompt approval more extraordinarily than administration for deliberations in piles. This is the result of individual knowledge contributing to the whole organization. Since both companies were raising the multi-skilled worker, it was able to respond flexibly also under the critical situation of an organization. Moreover, this multi-skilled worker training is backed by long-term employment, which is a special feature of Japanese management.

Systematic Kaizen was performed and the Renesas Electronics Corporation Naka Factory and Hitachi Transport System, Ltd. were able to recover from the critical situation. The Renesas Electronics CorporationNaka Factory actually restored the quantity of production that fell off to about $50 \%$ immediately after the earthquake disaster to $85 \%$ at the end of June. Although restoration took some time, the factory line for which the equipment, which required processing on a nano-level was needed, was restored on June 1st and the 6th. Moreover, as a result of 
securing a transportation route promptly, the shipping status of Hitachi Transport System, Ltd. came to recover from 70 \%to 100\% at the 2nd week in April 2011.

This time, about the organizational learning under a critical situation, the crisis management model that added Creative Learning to the correspondence of Japanese companies was built, and it was verified by the systematic crisis which Japanese companies called the Tohoku earthquake and tsunami, had not been experienced until it was now applicable to analysis.

As a result, the point, which runs short only by Single-Loop Learning and Double- Loop Learning was clarified about organizational learning when the critical situation occurred. The author thinks that he would like to examine utilizing this as a tool for performing this verification model organization-employment under a critical situation, and improvements from now on. 


\section{References}

i. $\quad$ Ando, F., 2001. Comparison of 3 Systems in the Organization Learning Theory. Japan Society of Business Administration, Volume 71, pp. 112-117.

ii. Aoki, M., 2003. Organizational Capabilities and Financial Performance. Management Journal, Volume 5, pp. 25-45.

iii. Argyris, C., 1982. Organizational Learning and Management Information System, s.l.: DATABASE.

iv. $\quad$ Argyris, C. \& Schon, D. A., 1978. Organizational Leaning : A Theory of Action Perspective, s.l.: Addison-Wesley Publishing Company.

v. $\quad$ Barnett, C., 1994. Organizational Learning Theories : A review and synthesis of the literature, s.l.: Academy of Management Review.

vi. Choo, H., 2003. The Framework of Strategic Organizaional Learning. Mita Business Review, 46(4), p. 49-71.

vii. Ebizawa, E., 1987. A Principle of Organizational Learning Process. The review of economics and commerce, 22(3-4), pp. 1-25.

viii. Iwasaki, K., 2012. Competitive Advantage in Service Industry : Relationship between Quality and Profitability. Kaetsu University research review, 54(2), pp. 89-107.

ix. Lalonde, C., 2007. CrisisManagementAndOrganizationalDevelopment TowardsTheConceptionOf A LearningModelInCrisisManagement. Organization Development Journal, Volume 25, pp. 507-517.

x. Levitt, B. \& March, J. G., 1988. Organizational learning. Annual Review of Sociology, Volume 14, pp. 319-340.

xi. March, J. G. \& Simon, H. A., 1958. Organizations, s.l.: John Wiley \& Sons.

xii. $\quad$ Miles, R. E. \& Snow, C. C., 1978. Organizational Strategy, Structure, and Process, s.l.: s.n.

xiii. Puncan, R. \& Weiss, A., 1979. Organizational Learning : Implications for Organizational design. In: B. M.Staw, ed. Research in Organizational Behavior. s.l.:Jl Press Inc.

xiv. Shiraishi, H., 2009. Organizational Learning and Learning Organizatio. Kanazawa University Economic Review, 29(2), pp. 233-261.

xv. Simmons, C., 2009. Crisis Management \& Organizational Learning. How Organizations Learn from Natural Disasters, s.l.: SSRN eLobrary Collection.

xvi. Uchida, J., 2008. Study about the roots for competence of Enterprise Organization Part2 : Case Study on SHARP. Journal of International Association of Project \& Program Management, 3(1), pp. 159-168.

Asia Pacific Institute of Advanced Research (APIAR) DOI : 10.25275/apjabssv4i1bus8 